\title{
Comparison of current and emerging strategies for treating hepatic encephalopathy.
}

1. MBBS, M.Phil

Assistant Professor Biochemistry Bahria University Medical and Dental College, Karachi.

2. MBBS, M.Phil

Demonstrator Physiology Gujranwala Medical College, Gujranwala.

3. MBBS, MCPS

Medical Officer

Sir Ganga Ram Hospital, Lahore.

4. BDS

Senior Lecturer Biochemistry

Bahria University Medical and

Dental College, Karachi.

5. MBBS, M.Phil

Professor Biochemistry Bahria University Medical and Dental College, Karachi.

6. MBBS, FCPS

Professor Physiology

Bahria University Medical and

Dental College, Karachi.

Correspondence Address:

Dr. Sadia Rehman

Department of Biochemistry

Bahria University Medical and Dental

College, Karachi.

dr.sadia89@hotmail.com

Article received on:

10/06/2021

Accepted for publication:

21/08/2021

\begin{abstract}
Sadia Rehman ${ }^{1}$, Qurat UI Ain Fatima ${ }^{2}$, Suniya Rehman ${ }^{3}$, Zara Sami ${ }^{4}$, Hasan Ali5, Irum Saddiqa ${ }^{6}$
ABSTRACT... Objective: To compare the efficacy of rifaximin and metronidazole which are the most commonly used antibiotics used in treating this disorder. Study Design: Randomized Controlled Trial. Setting: Department of Medicine, Sharif Trust Hospital. Period: Jan 2018 to July 2018. Material \& Methods: In this study cirrhotic patients irrespective of etiology were enrolled. West Haven Criteria (WHC) was utilized for grading the symptoms of $\mathrm{HE}$ at baseline and after 7 days of treatment. The study subjects were further subdivided into two groups: rifa group and metro group, and were given rifaximin and metronidazole respectively along with lactulose. The efficacy of the treatment and adverse effects in both the groups were estimated. Results: Total 180 subjects with HE (grade- III or IV) were selected, 90 subjects were subdivided into each group. Out of 90 subjects of Rifa group, efficacy of treatment was noted in 14 (15\%) patients and out of 90 subjects of Metro Group, treatment was found effective in $45(50 \%)$ patients with $p$ value of 0.0001 . Conclusion: The conclusion of this study is that metronidazole is superior to rifaximin in terms of efficacy in the management of an acute phase of hepatic encephalopathy due to chronic liver cirrhosis. Hence, due to its cheaper cost and a good safety margin its use is recommend in poor resource settings.
\end{abstract}

Key words: Hepatic Encephalopathy, Metronidazole, Lactulose, Rifaximin.

Article Citation: Rehman S, Fatima Qurat UI Ain, Rehman S, Sami Z, Ali H, Saddiqa I. Comparison of current and emerging strategies for treating hepatic encephalopathy. Professional Med J 2021; 28(12):1705-1710. https://doi.org/10.29309/TPMJ/2021.28.12.6644

\section{INTRODUCTION}

Hepatic encephalopathy (HE) is a combination of metabolic disorders ranging from hepatic impairment and progressing up to neuropsychiatric manifestations ${ }^{3}$ The factors causing $\mathrm{HE}$ include bleeding and infections of the gastrointestinal tract, constipation, hypoglycemia, electrolyte imbalances, certain medications which include opiates and sedativehypnotics. Cirrhotic patients usually have a bad nutritional status due to anorexia, nausea, malabsorption, and an altered metabolism. ${ }^{6}$ The poor dietary status due to anorexia leads to a deficiency of branched chain amino acids and result in accumulation of aromatic amino acids, both worsening protein-energy malnutrition and glutaminergic neurotransmission. ${ }^{10}$ Major part of the ammonia production in the gut is by the deamination of dietary amino acids by intestinal bacteria and some contribution is also made by urease-positive bacteria. Prompt detection and treatment of these factors can lead to lower morbidity status in these patients. ${ }^{4}$

Presently the main target of management of $\mathrm{HE}$ is to decrease the levels of ammonia in order to stop the induction of glutamate neurotoxicity. ${ }^{6}$ Many therapeutic agents have been used for the treatment of these complications of end-stage liver disease. ${ }^{7}$ These medications reduce the formation of ammonia by reducing its absorption from the gastrointestinal tract. The aggravating factors like electrolyte imbalances, constipation and gastrointestinal hemorrhage are also corrected. ${ }^{20}$

The mainstay treatment for acute and chronic $\mathrm{HE}$ is the use of non-absorbable disaccharides like lactulose because they decrease the absorption of ammonia through from the small 
intestine by altering the $\mathrm{pH}$ of the colon. Which is a carbohydrate passes through the small bowel without being digested. ${ }^{21}$ In the colon fermentation of lactulose by anaerobic bacteria takes place. The fermentation of lactulose yields weak acids and gases which leads to alteration of the $\mathrm{pH}$ of the colon which causes the acidification of ammonia resulting in formation of ammonium ion which is poorly absorbed. ${ }^{8}$ Some oral antibiotics like paromomycin, neomycin, vancomycin, metronidazole and rifaximin are also effective in lowering the serum ammonia levels by decreasing the gut flora. Neomycin is an antibiotic which is effective during acute phase of the syndrome. However metronidazole is commonly used for the prevention and treatment of hepatic encephalopathy. These therapeutic agents are associated with adverse effects and also therapeutic compliance. ${ }^{16}$ Thus the treatment of $\mathrm{HE}$ is dependent on its severity. Treatment of causative factor is the first line of treatment as majority of the patients develop $\mathrm{HE}$ because of a precipitating factor. Treatment of acute changes in the mental status is the next step. Lastly secondary prophylaxis is given to stop the recurrence of HE. The treatment options for HE are limited. Commonly used medications are rifaximin and lactulose. Second line treatment options include probiotics, branched chain amino acids and ammonia scavengers. ${ }^{14,17,20}$

Rifaximin which is derived from rifamycin, acts by inhibiting the synthesis of the bacterial RNA. Rifaximin is a broad spectrum antibiotic and acts against both the aerobic and anaerobic gram-positive and negative microorganisms within the gastrointestinal tract. ${ }^{9}$ Previous studies have reported that rifaximin reduces the plasma ammonia concentration and leads to improvement in the symptoms of hepatic encephalopathy in patients suffering from liver disease. ${ }^{10,14}$ Rifaximin has is more favorable therapeutic option in terms of tolerability and side effects. ${ }^{18}$

This study was planned for comparing the efficacy of rifaximin and metronidazole in the management of hepatic encephalopathy.

\section{MATERIAL \& METHODS}

This study is an open label randomized controlled trial conducted in the Department of Medicine, in a private sector teaching hospital in Lahore Pakistan from Jan 2018 to July 2018. it was reviewed and approved by Ethical Research Board 9SMDC/SIAHS/441).

Inclusion criteria was all cirrhotic patients irrespective of etiology, with age 40-60 years; admitted with acute onset of grade-III to IV hepatic encephalopathy admitted in the Department of Medicine, Sharif Trust Hospital; Lahore from Jan 2018 to July 2018 were enrolled.

Exclusion criteria was patients with meningitis, encephalitis, cerebrovascular accident, malignancy by CT scan, CSF examination and MRI brain; Diabetic ketoacidosis, renal failure, and/or with sepsis were excluded.

The study subjects included patients older than 40 years diagnosed with chronic liver disease along with development of reversible neurological decline. The effectiveness of the treatment regime was estimated by the number of patients who had shown clinical improvement of the symptoms of $\mathrm{HE}$ during the course of treatment. To estimate the neurological response, mental status scoring was done by using Conn's classification. According to this classification subjects were graded as grade 0 to 4 . Grade 0 consisted of patients with no personality or behavioral abnormality. Grade 1 patients had disorientation, shortened attention span, anxiety or euphoria, or inability to add or subtract. Grade 2 subjects had disorientation in time, personality change or inappropriate behavior along with lethargy. Grade 3 subjects were those who had gross disorientation, confusion or bizarre behavior, somnolence, responsiveness to stimuli. Grade 4 subjects were those who had coma.

The asterixis was graded according to the established criteria as: Grade 0 with no tremors, grade 1 with few flapping motions grade 2 had occasional flapping motions, grade 3 with frequent flapping motions and grade 4 with almost continuous flapping motions. 


\section{Sample Size}

A sample size of 180 patients was calculated by using WHO calculator for sample size considering efficacy of Rifaximin (Rifa group) as $22.1 \%$ and Metronidazole (Metro group) as $78 \%$. The calculated sample size was 180 , so 90 participants were allocated in each group.

The improvement in severity of $\mathrm{HE}$ was calculated using West Haven Criteria after 7 days of admission. The patients were strictly monitored for any adverse effects throughout the study.

The patients in the Rifa group were given Rifaximin dose of 550mg B.D and the patients in the Metro Group were given Injection Metronidazole $500 \mathrm{mg}$ IV 8 hourly. In addition, the subjects of both the groups were also given a concomitant regimen of lactulose orally (dosage 15-30 ml) two to three times per day.

The data was entered in SPSS software, version 21. Quantitative variable like age was presented as mean $\pm S D$, while qualitative variable like gender, efficacy (Yes/No) was presented in frequency and percentages. To compare the frequency of efficacy in both groups Chi-square test was used. Effect modifier like age and gender were controlled through stratification. A P-value of $\leq$ 0.05 was considered to be significant statistically.

\section{RESULTS}

A total of 180 patients (90 patients in each group) with HE (grade- III or IV) were selected for the study. The mean of ages in both the groups was $49.43 \pm 6.866$ years.

In Rifa group the treatment efficacy was seen in 14 (23.33\%) patients and in Metro group, treatment was found effective in $45(75 \%)$ patients. The rate of efficacy was significantly higher in Metro group as compared to Rifa group with $p$ value 0.000 .

With respect to age our results revealed that in age group 40-50 years efficacy of treatment was noted in $6(13.33 \%)$ patients in Rifa group and in $39(86.66 \%)$ of the patients in metro group. In 51-60 years age group, a statistically significant difference in treatment efficacy was noted in 8 $(17.77 \%)$ and 27 (60\%) patients in Rifa and metro groups with a $p$ value 0.000 .

A total of 32 subjects of Rifa group and 32 patients of Metro group was found with grade 3 Hepatic encephalopathy. Efficacy of treatment was seen in $8(25 \%)$ patients and 24 (75\%) patients respectively and the difference was statistically significant with $p$ value 0.000 . A total of 28 patients of Rifa group and 28 patients of Metro group was found with grade 4 Hepatic encephalopathy. Efficacy of treatment was noted in 6 (21.43\%) subjects of Rifa group and 21 (75\%) patients in metro group with a $p$ value 0.000 .

\begin{tabular}{|c|c|}
\hline Variable & Mean \pm SD \\
\hline $\begin{array}{l}\text { Age (years) } \\
\text { Rifa group } \\
\text { Metro group }\end{array}$ & $\begin{array}{c}46.42 \pm 12.75 \\
46.37 \pm 12.75 \\
46.5 \pm 10.03\end{array}$ \\
\hline $\begin{array}{l}\text { Gender (M / F) } \\
\text { Rifa group } \\
\text { Metro group }\end{array}$ & $\begin{array}{l}90 / 90 \\
37 / 23 \\
33 / 27\end{array}$ \\
\hline $\begin{array}{l}\text { Hepatic Encephalopathy } \\
\text { Grade III } \\
\text { Rifa group } \\
\text { Metro group } \\
\text { Grade IV } \\
\text { Rifa group } \\
\text { Metro group }\end{array}$ & $\begin{array}{l}32 \\
32 \\
\\
28 \\
28\end{array}$ \\
\hline
\end{tabular}

\begin{tabular}{|c|c|c|c|c|}
\hline \multirow{2}{*}{ Treatment Group } & \multicolumn{2}{|c|}{ Hepatic Encephlopathy } & \multirow{2}{*}{ Total } & \multirow{2}{*}{ P-Value } \\
\hline & Improved & Not Improved & & \\
\hline $\begin{array}{l}\text { Rifa Group } \\
\text { Metro Group }\end{array}$ & $\begin{array}{l}14(15) \\
50(55)\end{array}$ & $\begin{array}{c}76(84.4) \\
40(45)\end{array}$ & $\begin{array}{l}90 \\
90\end{array}$ & $\begin{array}{l}0.000 \\
0.000\end{array}$ \\
\hline
\end{tabular}




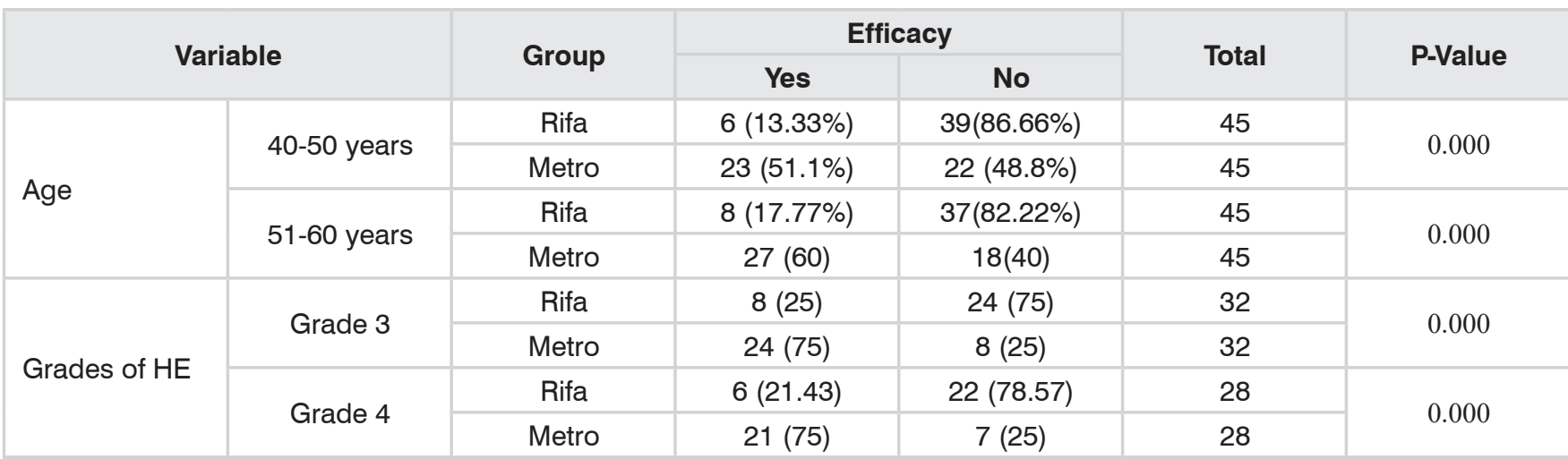

Table-III. Comparison of efficacy among different groups.

\section{DISCUSSION}

Hepatic encephalopathy is a clinical complication of chronic liver disease and has a wide spectrum of neuropsychiatric symptoms. These symptoms range from mild abnormality in the cognitive function to coma to even death. ${ }^{14}$ Traditionally, the first-line therapy for HE was non-absorbable disaccharides. ${ }^{14}$ The adjustment of disaccharide dose in order to get two to three bowel movements per day often leads to side effects like nausea, vomiting, flatulence and poor drug compliance. ${ }^{13}$ Oral antibiotics such as neomycin, vancomycin or paromomycin are more useful than disaccharides and have less side effects, but have a risk of toxicity. ${ }^{13,16}$ Due to this risk of toxicity, these agents are not commonly used in clinical practice now a days. ${ }^{19}$

Our hypothesis that rifaximin is better than metronidazole with respect to efficacy in treatment of hepatic encephalopathy was rejected as our study results came out in favor of metronidazole with significant $p$ value. This result is contrary to the observation by Mekky A et. ${ }^{15}$ in which they found both the drugs were of equal efficacy. In one study, rifaximin was found effective in $22.1 \%$ cases of hepatic encephalopathy. ${ }^{12}$ While according to another study ${ }^{13}$, metronidazole is effective in $78 \%$ patients.

With respect to age our results revealed that metronidazole is a better treatment option in both age groups. These findings are similar to the findings of Ridola et al. ${ }^{4}$

Rifaximin is an antibiotic that is effective in the management of hepatic encephalopathy with minimum side effects. ${ }^{19}$ It is well tolerated with minimum risk of developing bacterial resistance. In order to compare efficacy of rifaximin and metronidazole we performed an open label randomized controlled trial. In our study $75 \%$ patients of metro group showed clinical improvement in signs and symptoms of hepatic encephalopathy as compared to $23.3 \%$ in the rifa group. Moreover, it is a much cheaper option than rifaximin. Thus in the setting of limited resources, metronidazole is effective option in terms of efficacy and cost effectiveness.

The prolonged use of metronidazole is associated with ototoxicity, nephrotoxicity, neurotoxicity and reversible encephlopathy. ${ }^{14}$ In patients with decompensated liver disease, metabolism of metronidazole is affected which results into decreased hepatic clearance and increased concentration of cerebrospinal fluid leading to toxicity at a relatively low total cumulative dose of $22 \mathrm{~g} \cdot{ }^{17,18}$ Hence the long term use of metronidazole is not recommended. ${ }^{14}$

There are some limitations of our study like openlabel design with small sample size and a single center study. Furthermore, we did not categorize the patient according to etiology of cirrhosis and severity of liver cirrhosis was not assessed. There is another limitation in our enrolled patients that all of them were in higher grade of Hepatic encephalopathy. This limits the application of our recommendations to cover all Hepatic encephalopathy grades. 


\section{CONCLUSION}

Our study can be concluded that in terms of efficacy metronidazole is a better option as compared to rifaximin in the treatment of hepatic encephalopathy due to cirrhotic liver disease. Hence, its use is recommended in low resource healthcare settings because of its cheaper cost and a good margin of safety.

Copyright(c) 21 Aug, 2021.

\section{REFERENCES}

1. Dhiman RK, Thumburu KK, Verma N, Chopra M, Rathi S, Dutta U, Singal AK, Taneja S, Duseja A, Singh M. Comparative efficacy of treatment options for minimal hepatic encephalopathy: A systematic review and network meta-analysis. Clinical Gastroenterology and Hepatology. 2020 Apr 1; 18(4):800-12.

2. Bajaj JS, Lauridsen M, Tapper EB, Duarte-Rojo A, Rahimi RS, Tandon P, Shawcross DL, Thabut D, Dhiman RK, Romero-Gomez M, Sharma BC. Important unresolved questions in the management of hepatic encephalopathy: An ISHEN consensus. American Journal of Gastroenterology. 2020 Jul 1; 115(7):9891002.

3. Lee EW, Lee AE, Saab S, Kee ST. Retrograde Transvenous Obliteration (RTO): A new treatment option for hepatic encephalopathy. Digestive Diseases and Sciences. 2020 Jan 31:1-9.

4. Ridola L, Riggio O, Gioia S, Faccioli J, Nardelli S. Clinical management of type $C$ hepatic encephalopathy. United European gastroenterology journal. 2020 Jun; 8(5):536-43.

5. Sun X, Lv Y, Huang L, Gao H, Ren C, Li J, Bie M, Li W, Koike K, So KF, Xiao J. Pro-inflammatory cytokines serve as communicating molecules between the liver and brain for hepatic encephalopathy pathogenesis and Lycium barbarum polysaccharides protection. Journal of Ethnopharmacology. 2020 Feb 10; 248:112357.

6. Prasad S, Dhiman R, Duseja A, Chawla Y, Sharma A, Agarwal R. Lactulose improves cognitive function and health-related quality of life in cirrhotic patients with minimal hepatic encephalopathy. Hepatology 2007; 45:549-59.

7. Abid S, Kamran M, Abid A, Butt N, Awan S, Abbas Z. Minimal Hepatic Encephalopathy: Effect of $H$. pylori infection and small intestinal bacterial overgrowth treatment on clinical outcomes. Scientific reports. 2020 Jun 22; 10(1):1-7.
8. Bass N, Mullen K, Sanyal A, Poordad F, Neff G, Leevy C. Rifaximin treatment in hepatic encephalopathy. $\mathrm{N}$ Engl J Med 2010; 362:1071-81.

9. Coronel-Castillo CE, Contreras-Carmona J, FratiMunari AC, Uribe M, Méndez-Sánchez N. Efficacy of rifaximin in the different clinical scenarios of hepatic encephalopathy. Revista de Gastroenterología de México (English Edition). 2020 Jan 1; 85(1):56-68.

10. Butterworth RF. Beneficial effects of L-ornithine L-aspartate for prevention of overt hepatic encephalopathy in patients with cirrhosis: A systematic review with meta-analysis. Metabolic brain disease. 2020 Jan; 35(1):75-81.

11. Bass NM, Mullen KD, Sanyal A, Poordad F, Neff G, Leevy $\mathrm{CB}$, et al. Rifaximin treatment in hepatic encephalopathy. N Engl J Med. 2010 Mar 25; 362(12):1071-81.

12. Frati-Munari $R$, Galindo-Suárez M. Rifaximin-a in hepatic encephalopathy. Pharmaco-economic considerations for Mexico. Medicina Interna de México. 2020 Oct 1; 36(5):621-32.

13. Reinert JP, Burnham K. Non-Lactulose Medication Therapies for the Management of Hepatic Encephalopathy: A Literature Review. Journal of Pharmacy Practice. 2020 Sep 3:0897190020953024.

14. Leise MD, Poterucha JJ, Kamath PS, Kim WR. Management of hepatic encephalopathy in the hospital. Mayo Clin Proc. 2014 Feb; 89(2):241-53. doi: 10.1016/j.mayocp.2013.11.009.

15. Mekky MA, Riad AR, Gaber MA, Abdel-Malek MO, Swifee YM. Rifaximin versus metronidazole in management of acute episode of hepatic encephalopathy: An open labeled randomized clinical trial. Arab J Gastroenterol. 2018 Jun; 19(2):76-79. doi: 10.1016/j.ajg.2018.06.001.

16. Yamamoto $T$, Abe $K$, Anjiki $H$, Ishii $T$, Kuyama $Y$. Metronidazole-induced neurotoxicity developed in liver cirrhosis. J Clin Med Res. 2012 Aug; 4(4):295-8. doi: $10.4021 /$ jocmr893w.

17. Mulcahy H, Chaddha SK. MRI of MetronidazoleInduced Encephalopathy. Radiol Case Rep. 2015 Dec 7; 3(4):239. doi: 10.2484/rcr.v3i4.239.

18. Bohra A, Worland T, Hui S, Terbah R, Farrell A, Robertson M. Prognostic significance of hepatic encephalopathy in patients with cirrhosis treated with current standards of care. World Journal of Gastroenterology. 2020 May 14; 26(18):2221. 
19. Eltawil KM, Laryea M, Peltekian K, Molinari M. Rifaximin vs conventional oral therapy for hepatic encephalopathy: A meta-analysis. World journal of gastroenterology: WJG. 2012 Feb 28; 18(8):767.
20. XuXY, Ding HG, LiWG, Jia JD, Wei L, Duan ZP, Liu YL, Ling$\mathrm{Hu} E Q$, Zhuang $\mathrm{H}$, of Hepatology CS, Chinese Medical Association. Chinese guidelines on management of hepatic encephalopathy in cirrhosis. World journal of gastroenterology. 2019 Sep 28; 25(36):5403.

\begin{tabular}{l} 
AUTHORSHIP AND CONTRIBUTION DECLARATION \\
\begin{tabular}{|l|l|l|}
\hline No. & \multicolumn{1}{|c|}{ Author(s) Full Name } & Contribution to the paper \\
\hline 1 & Sadia Rehman & Main author and researcher. \\
2 & Qurat UI Ain Fatima & Data collection. \\
3 & Suniya Rehman & Data collection. \\
5 & Lara Sami & Literature review. \\
6 & Irum Saddiqa & Interpretation of results.
\end{tabular} \\
\hline
\end{tabular}

